6. Gilchrist V, McCord G, Labuda-Schrop S, et al. Physician activities during time out of the examination room. Ann Fam Med. 2005;3:494-499.

7. Schulberg HC, Lee PW, Bruce ML, et al. Suicidal ideation and risk among primary care patients with uncomplicated depression. Ann Fam Med. 2005;3:523-528

8. Nutting PA, Dickinson LM, Rubenstein L, Elliott CE, Keeley RD. Improving detection of suicidal ideation among depressed patients in primary care. Ann Fam Med. 2005;3:529-536.
9. Beasley JW, Karsh B, Hogenauer M, Marchand L, Sainfort F. What is the quality of work life of independent vs employed family physicians in Wisconsin? A WRen Study. Ann Fam Med. 2005;3:500-506.

10. Elder NC, Jacobson J, Zink TM, Hasse L. How experiencing preventable medical problems has changed patients' interactions with primary healthcare. Ann Fam Med. 2005;3:537-544.

11. Weiss BD, Mays MZ, Martz W, et al. Quick assessment of literacy in primary care: the newest vital sign. Ann Fam Med. 2005;3:514-522.

12. Buetow SA. To care is to coprovide. Ann Fam Med. 2005:3:553-555.

\title{
EDITORIAL
}

\section{Doing Things Better vs Doing Better Things}

\author{
Richard L. Kravitz, MD, MSPH \\ Center for Health Services Research in Primary Care, University of California, Davis, Sacramento, Calif
}

Ann Fam Med 2005;3:483-485. DOI: 10.1370/afm.407.

$\mathrm{T}$ The United States spends approximately $\$ 1.5$ trillion on health care each year (about $\$ 5,700$ per person), yet we have relatively little to show for it. Population health statistics (eg, years of healthy life expectancy) place the United States somewhere between Portugal and Slovenia. ${ }^{1}$ Part of the reason for America's poor showing is that treatments known to be effective are not reliably delivered to the people who need them. The problem has been parsed many different ways, ${ }^{2-4}$ but most authorities would agree that poor access to care, flawed decision making, and error-prone implementation are the critical dimensions. There is plenty of evidence for unsatisfactory performance along all 3 lines. The situation for the poor and for ethnic minorities is, not surprisingly, worse. ${ }^{5}$ Meanwhile, our nation continues to pour money into biomedical research in the hopes of discovering cures. In their essay in this issue of the Annals, Steven Woolf and Robert Johnson ask a novel and pertinent question: what would happen if we devoted more resources to doing

Conflict of interest: none reported

\section{CORRESPONDING AUTHOR}

Richard L Kravitz, MD, MSPH

Center for Health Services in Primary Care

University of California, Davis

2103 Stockton Blvd

2226 Grange Bldg

Sacramento, CA 95817

rlkravitz@ucdavis.edu what we do better, rather than looking for new things to do. They introduce a new term, fidelity, to describe what others have called integration-making sure that what we know to be beneficial actually gets done. The answer-that we may well be better off if we shifted resources from discovery to fidelity-may surprise some people.

Woolf and Johnson do some calculations that show how, in at least 2 cases, increasing the delivery of treatments with known effectiveness would save more lives than discovering new treatments, unless those new treatments represented astounding advances over current therapy. In one example, new antiplatelet treatments to prevent stroke would have to be $74 \%$ more effective than aspirin to generate the same benefits as a behavioral intervention designed to increase aspirin use from $58 \%$ of eligible patients (which is the current national average, according to a RAND study ${ }^{6}$ ) to $100 \%$. In another example, new cholesterol-reducing agents would need to be 3 times as potent as current statins to equal the mortality benefits of ensuring that the older statins are actually taken by $100 \%$ of eligible patients.

Lamentations about lack of scientific progress against dread diseases are not new. The war on cancer, for example, strikes some as a quagmire. ${ }^{7}$ What is bracing here are the cold, hard numbers. They show explicitly the trade-offs between discovery and integration.

Resources committed to one front may be opportunities lost on the other.

A few of the authors' assumptions and some of their logic invite scrutiny. For a variety of reasons, the esti- 
mates of underuse developed by RAND 6 may be overly dire. Some indicators are based on tenuous evidence linking process with outcomes. And some of the indicators do not adequately account for contraindications, patient preferences, and "what physicians know" about the individual patient's pathophysiology, functional status, and values. ${ }^{8}$ The supposition that treatment fidelity rates are uniform across patient risk groups is also questionable. For a variety of reasons, high-risk patients (ie, those with a higher likelihood of suffering a disease-related adverse event) may be more likely to be "treated to guideline" than lower risk patients. In addition, the absolute benefits of treatment are almost invariably greater among higher risk patients. ${ }^{9}$ If highrisk patients are both more likely to be treated and more likely to benefit from treatment, there may be less benefit available for harvest from improving adherence to guidelines.

Woolf and Johnson undervalue biotechnology even as they oversell fidelity. They argue that biotechnological advances are counterbalanced by a much larger number of failures, but this argument is a straw man. The more important issue is the marginal cost of new discoveries compared with their marginal benefits. If the incremental cost of producing a "me-too" statin is low, the drug may still be a good buy for society as long as it offers modest advantages to one or more patient subgroups.

At an even more fundamental level, the article overlooks the bitter truth that if efficacy is poor, fidelity doesn't matter. One hundred percent access to arsenicals for syphilis would have produced few benefits. The older statins were themselves the product of remarkable laboratory and translational research efforts. The previous standard therapies, cholestyramine and niacin, were not only less effective but also more difficult to tolerate. Twenty years ago, many of today's standard therapies did not exist. How many of us would wish to live in a world without ACE-inhibitors, serotonin-specific reuptake inhibitors, inhaled corticosteroids, antiretroviral medications, coronary angioplasty, or magnetic resonance imaging scans?

Nevertheless, the main point of the article - that we as a society spend far too little putting research into practice-is incontrovertible. The benchmark for quality in modern industry is " 6 sigma" ( 3.4 errors per million attempts). Industries striving for 6-sigma quality invest up to $1 \%$ of gross revenues in quality assurance and improvement. One percent of the $\$ 1.5$ trillion in US health care expenditures comes to $\$ 15$ billion, or about one half the current NIH budget. We do not spend nearly enough on all aspects of quality, including efforts to address overuse, underuse, and misuse. (The latter is particularly important, as the benefits of improved fidelity in Woolf and Johnson's two examples will rapidly diminish if aspirin is prescribed to patients with a history of severe gastrointestinal bleeding, or if statins are continued in patients complaining of severe muscle aches.)

The reasons for our eagerness to invest heavily in biotechnology while virtually ignoring fidelity are probably more complex than they first appear. Economic factors matter (there's no profit, or very little, in quality), and pay-for-performance schemes deserve wider implementation (coupled with careful evaluation so perverse incentives are minimized). Factors other than economic ones are likely important as well. In a widely cited essay, Boyer describes 4 domains of scholarship: discovery, integration, education, and application. ${ }^{10}$ Discovery surely fires the public and professional imagination in a way that integration, education, and application-all critical to fidelity in health care-do not. Part of the blame rests with the media, which tends to overemphasize the benefits and underrepresent the risks of new therapeutic approaches. ${ }^{11}$ It is up to translational researchers to convey the excitement of using the social, behavioral, and information sciences to solve real problems. The public may be ready; after all, the Institute of Medicine reports on health care quality, medical errors, and health disparities have found wide resonance. Woolf and Johnson's engaging and highly original article presents a challenge. All of us involved in the scholarship of integration, education, and application in health care need to become fierce advocates for doing things better, even as our laboratory colleagues continue searching for better things to do.

To read or post commentaries in response to this article, see it online at http://www.annfammed.org/cgi/content/full/3/6/483.

Key words: Allocation of resources; delivery of health care; priority setting; disparities; quality of health care

Submitted October 6, 2005; accepted October 12, 2005.

\section{References}

1. World Health Organization. World Health Statistics 2005. 2005. Available at: http://www.who.int/healthinfo/statistics/en/.

2. Brook RH. Managed care is not the problem, quality is. JAMA. 1997;278:1612-1614.

3. Chassin MR. Is health care ready for Six Sigma quality? Milbank Q. 1998;76:565-591, 510.

4. Maxwell RJ. Quality assessment in health. Br Med J (Clin Res Ed). 1984;288:1470-1472.

5. Smedley BD, Stith AY, Nelson AR. Unequal Treatment: Confronting Racial and Ethnic Disparities in Health Care. Washington, DC: Institute of Medicine. Committee on Understanding and Eliminating Racial and Ethnic Disparities in Health Care; 2003.

6. McGlynn EA, Asch SM, Adams J, et al. The quality of health care delivered to adults in the United States. N Engl J Med. 2003;348:2635-2645. 
7. Bailar JC, 3rd, Gornik HL. Cancer undefeated. N Engl J Med. 1997;336:1569-1574.

8. Tanenbaum SJ. What physicians know. N Engl J Med. 1993;329: 1268-1271.

9. Rothwell PM, Warlow CP. Prediction of benefit from carotid endarterectomy in individual patients: a risk-modelling study. European Carotid Surgery Trialists' Collaborative Group. Lancet. 1999;353:2105-2110.
10. Boyer E. Scholarship Reconsidered: Priorities of the Professoriate. Princeton, NJ: Carnegie Foundation for the Advancement of Teaching; 1990.

11. Bubela TM, Caulfield TA. Do the print media "hype" genetic research? A comparison of newspaper stories and peer-reviewed research papers. CMAJ. 2004;170:1399-1407.

\section{EDITORIAL}

\section{Misaligned Incentives in America's Health: Who's Minding the Store?}

Steven M. Teutsch, MD, MPH

Marc L. Berger, MD

Outcomes Research and Management, Merck \& Co, Inc, West Point, Penn

Ann Fam Med 2005;3:485-487. DOI: 10.1370/afm.408.

W e share Woolf and Johnson's pain. ${ }^{1}$ The American health care system simply fails to deliver the health benefits commensurate with our investment. We have no one to blame but our collective selves, however. Each group of constituents is intent on trying to do its best while responding to misaligned incentives. Clinicians are working harder and are under increased scrutiny to show that they are up-to-date with evolving treatment guidelines. Scientists are making extraordinary advances in our understanding of the basic mechanisms underlying bodily functions and how they malfunction in disease. Private research and development enterprises are harnessing cutting edge technologies (eg, combinatorial chemistry, high-throughput screening, genetic/proteomic profiling) to translate these basic science insights into potential diagnostics and treatments. Payers are increasing incentives to clinicians to provide appropriate care

Conflicts of Interest: None. The authors are employees and stock and options bolders of Merck \& Co, Inc. No products are addressed in this editorial.

\section{CORRESPONDING AUTHOR}

Steven M. Teutsch, MD, MPH

Outcomes Research and Management

Merck \& Co, Inc.

PO Box 4, WP 39-130

West Point, PA 19486-0004

steven_teutsch@merck.com according to evidence-based guidelines. Yet our health indices are poor by any reasonable metric. We fail to provide health insurance to a large segment of the population; we fail to deliver effective services about one half the time to persons who need them; and we fail to organize our society to reduce unhealthy behaviors. So what is the way forward?

H. L. Mencken once said, "There is always a wellknown solution to every human problem-neat, plausible, and wrong."2 We agree with Woolf and Johnson that better balance in our social investment would likely improve the overall health of the population. We should not assume, however, that closing the treatment gap will be easier or less costly than developing new health technologies; indeed, history would suggest such is not the case. After 1 year, one half of new patients with chronic conditions no longer take their regular medications. Health Plan Employer Data and Information Set (HEDIS) measures suggest that among those with access to care, many effective services remain underutilized, even with the incentive of public reporting. ${ }^{3}$ Perhaps more disturbing is that effective population-based strategies are even more broadly ignored. The Guide to Community Preventive Services ${ }^{4}$ identifies many effective techniques for healthy behaviors, improving the sociocultural environment, improving delivery of vaccines, and other health care services. All could increase longevity and quality of life, yet all are underutilized, and the research to identify and 